\title{
Peran Mediasi Kepercayaan pada Pengaruh Kepemimpinan Melayani Terhadap Kinerja Karyawan PT Nesinak
}

\author{
Indra Setiawan \\ Universitas Pelita Bangsa \\ Indra.setiawan@pelitabangsa.ac.id \\ Muhamad Ekhsan \\ Universitas Pelita Bangsa \\ Muhamad.ekhsan@pelitabangsa.ac.id
}

\begin{abstract}
The purpose of this study was to examine and explain the effect of serving leadership on employee performance mediated by trust. This research is quantitative descriptive. The data were collected using an instrument in the form of a questionnaire. The sample of this research is 75 employees of PT Nesinak's production department. The analytical method for testing the hypothesis in this study is Partial Least Square (PLS). The results showed that serving leadership had a positive and significant effect on employee performance, the trust had a positive and insignificant effect on employee performance, the trust had a positive and significant effect on employee performance, serving leadership had a positive and significant effect on employee performance through trust.
\end{abstract}

Keywords Servant leadership, trust, employee performance, strategy

\section{PENDAHULUAN}

Sumber daya manusia tidak hanya diartikan sebagai apa yang dikerjakan oleh sumber daya manusia, tetapi juga apa yang dihasilkan oleh sumber daya manusia. Sumber daya manusia memainkan peran yang lebih besar dalam keberhasilan organisasi, sehingga banyak organisasi sekarang menyadari bahwa elemen "manusia" dalam organisasi dapat memberikan keunggulan kompetitif (King et al., 2016), dan perilaku sumber daya manusia serta hasil produksi tidak dapat dibedakan darinya. Kinerja adalah konsep yang menggambarkan bagaimana seseorang menggunakan potensi atau pengetahuan, keterampilan dan kemampuan mereka untuk mencapai tujuan atau harapan mereka (Altındağ \& Kösedağı, 2015)

Kepemimpinan organisasi merupakan faktor penting dalam proses atau upaya untuk meningkatkan kinerja pribadi dan organisasi. Kepemimpinan adalah kemampuan untuk mempengaruhi, menginspirasi, dan berkontribusi secara pribadi terhadap efektivitas dan perkembangan perusahaan (Dartey-Baah, 2015). Kepemimpinan mempunyai beberapa jenis, diantaranya kepemimpinan otoriter, kepemimpinan karismatik, dan kepemimpinan yang melayani. Kepemimpinan yang paling efektif diantara ketiganya adalah kepemimpinan melayani (Shekari \& Nikooparvar, 2012)

Kepemimpinan berorientasi pelayanan merupakan salah satu jenis kemampuan kepemimpinan yang dapat memberdayakan dan mengembangkan karyawan dengan sikap rendah hati, tulus dan hormat. Pemimpin layanan akan memberikan arahan dan bertanggung jawab atas organisasi atau perusahaan yang dipimpinnya (van Dierendonck 
\& Nuijten, 2011). Karakteristik in-service leader adalah kemampuan konseptual yang kuat, integritas tinggi, dan kepedulian terhadap bawahan. Selain itu, in-service leader secara aktif menekankan bahwa bawahan juga harus menempatkan kebutuhan orang lain di atas dirinya sendiri, sehingga mendorong bawahan untuk mempraktikkan perilakunya sendiri (Liden et al., 2014).

Penggunaan kepercayaan sebagai variabel mediasi didasarkan pada pertimbangan hasil-hasil penelitian yang telah dilakukan sebelumnya. Penelitian tentang hubungan antar kepemimpinan melayani dengan kepercayaan dilakukan oleh Rezaei (2012). Penelitian mengenai hubungan kepercayaan dengan kinerja karyawan telah dilakukan oleh brown et al (2015). Paliszkiewicz (2012) yang menjelaskan bahwa kepercayaan yang dimiliki oleh karyawan mampu memberikan dampak terhadap kinerja karyawan.

PT Nesinak merupakan perusahaan rubber part yang beroperasi di Kawasan industri Delta Silicon, Cikarang. PT Nesinak berkomitmen untuk membina sumber daya manusia yang profesional dan berkualitas, karena sumber daya manusia yang berkualitas merupakan aspek penting dalam menjaga persaingan utama dan menjadi salah satu faktor penting yang mendukung terwujudnya tujuan organisasi atau perusahaan. Peneliti melihat banyak aspek untuk menentukan kinerja perusahaan, salah satunya adalah memeriksa pencapaian tujuan produksi setiap tahunnya. Kinerja karyawan di PT Nesinak masih sangat rendah, karena target yang ditetapkan perusahaan tidak tercapai berdasarkan data produktivitas selama satu tahun terakhir, khususnya untuk bagian produksi.

Berikut merupakan data grafik pencapaian kinerja karyawan departemen produksi bagian cutting periode mei 2019 - April 2020

Tabel 1. Produktivitas Produksi Bagian Cutting Periode Mei 2019 - April 2020

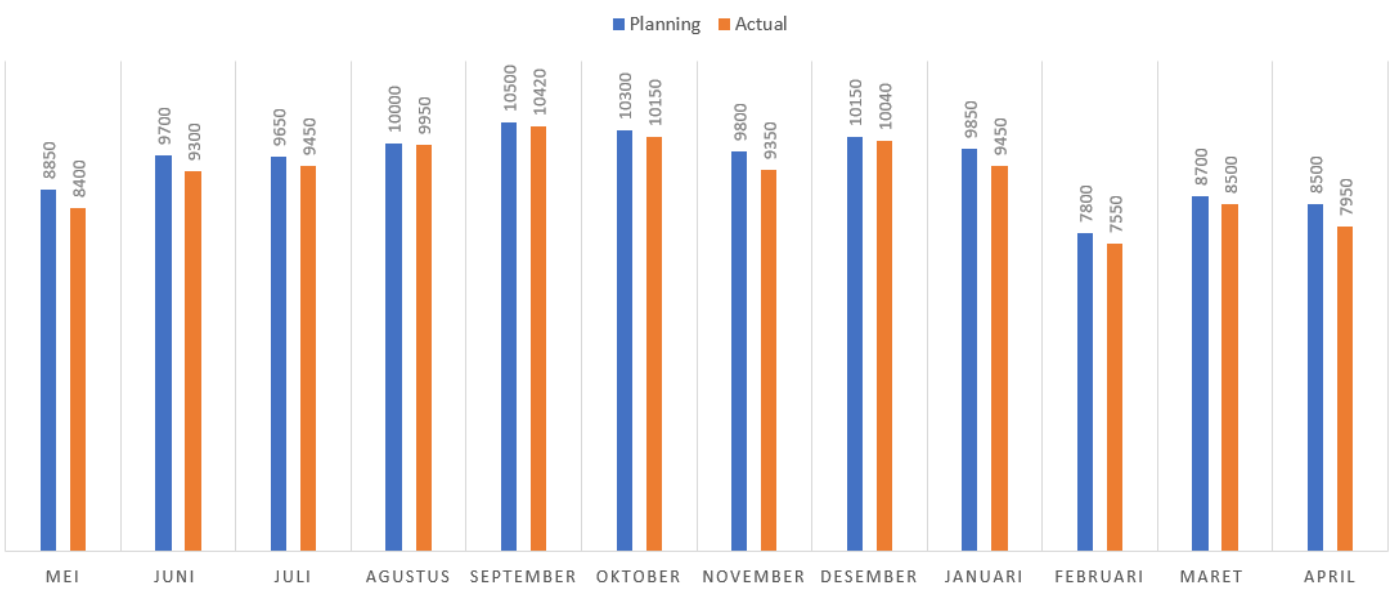

Berdasarkan tabel 1. dapat diketahui bahwa jumlah perencanaan pada PT. Nesinak departemen produksi bagian cutting dari bulan Mei 2019 sampai bulan April 2020 pencapaiannya belum mencapai target yang sudah ditentukan. Perencanaan maksimal yang dapat dihasilkan terjadi pada bulan Agustus, sedangkan perencanaan minimal terjadi pada bulan April. Hal ini membuktikan bahwa kinerja setiap karyawan belum optimal yang disebabkan beberapa faktor seperti kurangnya ketepatan waktu dalam menyelesaikan pekerjaan, serta adanya pengaruh dari kepemimpinan yang kurang 
melayani menyebabkan karyawan kurang mentaati apa yang diharapkan oleh pimpinannya.

Peningkatan kinerja pegawai merupakan faktor penentu dalam peningkatan kinerja organisasi, karena semakin rendah tingkat produktivitas pegawai maka produktivitas perusahaan akan semakin rendah. Jika produktivitas perusahaan rendah maka tujuan organisasi akan sulit tercapai. Kinerja karyawan PT Nesinak memang sangat rendah, banyak faktor yang dapat mempengaruhi hal tersebut, mulai dari gaya kepemimpinan yang kurang tepat yang diterapkan oleh perusahaan dan rendahnya kepercayaan karyawan terhadap organisasi. Kinerja karyawan merupakan aspek yang penting bagi perusahaan untuk mendikung organisasi dalam mencapai tujuan. Jadi, sumber daya manusia di harapkan melalui ketrampilan, perilaku, dan sikap dapat mencapai kinerja yang dibutuhkan dalam organisasi (Cania, 2014).

Berdasarkan fenomena yang telah disampaikan, maka rumusan masalah yang diangkat pada penelitian ini adalah, apakah kepemimpinan melayani berpengaruh terhadap kinerja karyawan, apakah kepemimpinan melayani berpengaruh terhadap kepercayaan, apakah kepercayaan berpengaruh terhadap kinerja karyawan, apakah kepemimpinan melayani berpengaruh terhadap kinerja karyawan yang di mediasi oleh kinerja karyawan. Hasil penelitian ini harapannya dapat berguna sebagai bahan masukan bagi pihak manajemen khususnya dan pihak lain yang tertarik kajian kepemimpinan melayani, kepercayaan dan kinerja karyawan

\section{LANDASAN TEORI}

\section{Kinerja Karyawan}

Kinerja karyawan merupakan aspek penting dalam perusahaan, karena kinerja karyawan yang baik memiliki pengaruh penting dalam pencapaian tujuan perusahaan. Kinerja adalah konsep yang dapat menjelaskan bagaimana seseorang menggunakan potensi atau pengetahuan, keterampilan, dan kemampuannya yang sebenarnya untuk mencapai tujuan atau harapannya (Altındağ \& Kösedağı, 2015). Mathis (2015) menyatakan bahwa kinerja pada dasarnya adalah apa yang dilakukan atau tidak dilakukan karyawan. Bakiev (2013) menemukan bahwa pengukuran kinerja adalah sebagai fenomena yang sangat luas dan ada di setiap sector dan disiplin. Kinerja adalah ouput dari semua masukan dan upaya yang di ambil selama proses tersebut. Akibatnya, untuk mengetahui apakah organisasi tertentu mencapai tujuannya, hal ini sangat penting untuk mengukur kinerja karyawan. Kinerja adalah ekspresi kuantitatif dan kualitatif di mana individu, tim atau perusahaan dapat mencapai tujuan yang ditetapkan. Thigpen et al (2012) menemukan bahwa pendekatan sistem yang komprehensif dapat digunakan untuk perbaikan kinerja yang berkesinambungan serta mendorong ide- ide inovatif untuk meningkatkan operasi organisasi, layanan dan proses serta untuk mencapai hasil yang diinginkan. Kinerja karyawan merupakan hasil kerja yang dihasilkan karyawan pada kurun waktu tertentu, terdapat beberapa ukuran dalam menetapkan kinerja karyawan.

\section{Kepemimpinan Melayani}

Kepemimpinan adalah kemampuan untuk mempengaruhi, menginspirasi, dan berkontribusi secara pribadi terhadap efektivitas dan perkembangan perusahaan (DarteyBaah, 2015). Rai (2012) menemukan bahwa kepemimpinan yang melayani sebagai fasilitator pencipataan pengetahuan melaui perilaku seperti berbagi kepemimpinan dan hubungan peduli. Kepemimpinan melayani lebih fokus untuk melayani serta 
mengutamakan kepentingan pengikutnya. Bryant (2015) membahas tantangan yang dihadapi kepemimpinan yang melayani sebagai konstruk teoritis, khususnya sebagai definisi yang menghasilkan ketidakjelasan konstruk, kurang disepakatinya Langkahlangkah, dan jarang bukti empiris. Penelitian tersebut menjelaskan perlunya konsesus, penelitian empiris dan pemeriksaan fenomena kepemimpinan yang melayani di berbagai tingkat organisasi .

\section{Kepercayaan}

Robbins (2017) menjelaskan bahwa terdapat empat faktor kontekstual yang berhubungan dengan kinerja tim, yaitu sumber daya yang memadai, kepemimpinan yang efektif, iklim kepercayaan, evaluasi kinerja dan sistem penghargaan. Hal ini menunjukan bahwa kepercayaan yang ada dalam diri individu dalam organisasi dapat menghasilkan kinerja. Yukl (2013) menyatakan bahwa perhatian kepemimpinan melayani kepada bawahan akan menghasilkan peningkatan kepercayaan, loyalitas, komitmen kepercayaan dan kepuasan karyawannya terhadap pimpinannya. Olesia (2014) mengatakan bahwa para pemimpin tidak memiliki kuasa, kecuali diberi kepercayaan dari orang lain yang telah menyerahkannya kepada pemimpin. Dierendonck (2011) dalam penelitiannya menjelaskan bahwa pemimpin melayani mengembangkan pengikutnya untuk tumbuh dan sebagai orang yang lebih bijaksana, lebih sehat, lebih bebas, lebih otonom, dan melayani dirinya sendiri hal ini menimbulkan kepercayaan pengikutnya terhadap pimpinan karena lebih mementingkan pengikutnya menjadi mandiri.

\section{Pengembangan Hipotesis Penelitian}

Berdasarkan kajian teori dan review hasil penelitian terdahulu yang telah dipaparkan, dapat disimpulkan bahwa peningkatan kinerja karyawan secara umum dipengaruhi oleh berbagai faktor. Penelitian ini terfokus pada kepemimpinan melayani, kepercayaan dan kinerja karyawan. Berdasarkan uraian tersebut, maka dapat dirumuskan kerangka pemikiran sebagaimana tertera pada gambar berikut :

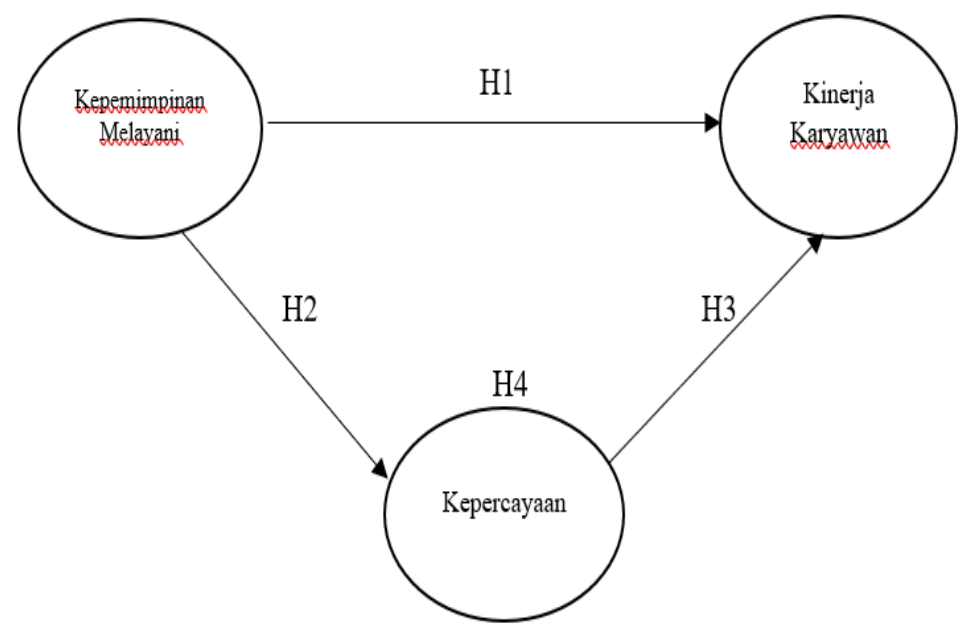

Gambar 1. Design Penelitian 
Hipotesis yang akan dikaji dalam penelitian ini adalah :

H1 : Kepemimpinan melayani berpengaruh positif dan signifikan terhadap kinerja karyawan

H2 : Kepemimpinan melayani berpengaruh positif dan signifikan tehadap kepercayaan

H3 : Kepercayaan berpengaruh positif dan signifikan terhadap kineja karyawan

H4 : Kepemimpinan melayani berpengaruh positif dan signifikan terhadap kinerja karyawan yang dimediasi kepercayaan

\section{METODOLOGI PENELITIAN}

Penelitian ini menggunakan metode deskriptif kuantitatif yang bertujuan untuk mendeskripsikan fakta, fenomena, peristiwa, gejala dan kejadian yang terjadi secara sistematis dan akurat dengan menggunakan angka-angka yang menggambarkan karakteristik objek penelitian. Objek penelitian di PT Nesinak, kawasan industri Delta Silicon III Cikarang. Teknik pengambilan sampel dalam penelitian ini adalah simple random sampling menggunakan rumus slovin berjumlah 75 responden. Penelitian ini menggunakan metode Structural Equation Model Smart PLS. Metode analisis data yang digunakan adalah uji R- square,Bootstrapping,Path Coefficient, dan Specific indirect effects.

\section{HASIL DAN PEMBAHASAN Pengujian Model Struktural}

Model struktural (inner model) dievaluasi dengan melihat nilai $R$-square. Pengujian model struktural (inner model) dilakukan setelah model hubungan yang dibangun dalam riset ini sesuai dengan data hasil observasi dan kesesuaian model secara keseluruhan (goodness of fit model). Berikut adalah tabel $R$-square dalam penelitian ini :

Tabel 2. $R$-square

\begin{tabular}{cc}
\hline & $R$-square \\
\hline Kinerja Karyawan & 0.723 \\
\hline Kepercayaan & 0.771 \\
\hline
\end{tabular}

Berdasarkan tabel $R$-square tersebut dapat disimpulkan bahwa : Model kepemimpinan melayani terhadap kinerja karyawan menghasilkan nilai $R$-square sebesar 0.723 yang artinya variabilitas konstruk kinerja karyawan dapat dijelaskan oleh variabel konstruk kepemimpinan melayani sebesar $72.3 \%$ sedangkan $27.7 \%$ dipengaruhi oleh variabel lain yang tidak diuji dalam penelitian ini. Model pengaruh variabel kepercayaan dengan nilai $R$-square 0.771 yang artinya variabilitas konstruk kepercayaan dengan variable terikat yaitu kepemimpinan melayani dan kinerja karyawan sebesar $77.1 \%$ sedangkan $22.9 \%$ dipengaruhi oleh variabel lain yang tidak diuji dalam penelitian ini.

Langkah selanjutnya setelah pengujian determinasi, maka dilakukan analisa jalur untuk mengetahui hubungan sebab akibat dengan tujuan menerangkan pengaruh langsung atau tidak langsung antar variabel eksogen dengan variabel endogen dengan melakukan analisa bootstrapping untuk mendapatkan prediksi dari hasil analisa jalur pada model penelitian ini.Berikut adalah gambar analisis jalur dengan analisa bootstrapping : 


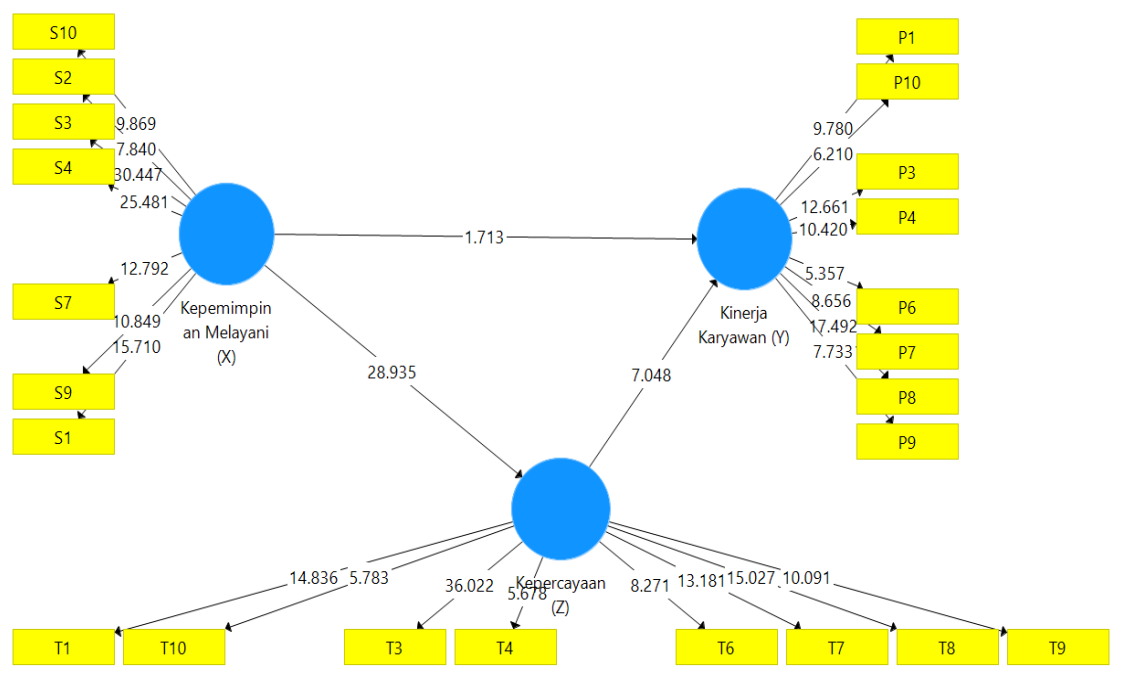

\section{Gambar 1. Bootstrapping}

\section{Pengujian hipotesis dan koefisien jalur pengaruh langsung dan tidak langsung}

Pengujian hipotesis dan koefisien jalur pengaruh secara langsung antara variabel yang diuji dapat dilihat dari hasil olah data melalui Path Coefficient dan Specific Indirect Effect yang menjelaskan nilai koefisien nilai $T$ value dan $P$ value untuk menjadi acuan hubungan sebab akibat pada model ini. Berikut adalah tabel Path Coefficient yang dapat menjelaskan pengaruh langsung antar variabel yang diuji :

Tabel 3. Path Coefficient

\begin{tabular}{lccccc}
\hline & $\begin{array}{c}\text { Original } \\
\text { Sample (O) }\end{array}$ & $\begin{array}{c}\text { Sample } \\
\text { Mean (M) }\end{array}$ & $\begin{array}{c}\text { Standard Deviation } \\
(\text { STDEV) }\end{array}$ & $\begin{array}{c}\text { T Statistics } \\
(|\mathrm{O} / \mathrm{STDEV}|)\end{array}$ & P Values \\
\hline $\begin{array}{l}\text { Kepemimpinan Melayani } \\
->\text { Kinerja Karyawan }\end{array}$ & 0.850 & 0.857 & 0.029 & 28.935 & 0.000 \\
\hline $\begin{array}{l}\text { Kepemimpinan Melayani } \\
\text { - Kepercayaan }\end{array}$ & 0.193 & 0.187 & 0.113 & 1.713 & 0.087 \\
\hline $\begin{array}{l}\text { Kepercayaan -> Kinerja } \\
\text { Karyawan }\end{array}$ & 0.708 & 0.719 & 0.101 & 7.048 & 0.000 \\
\hline
\end{tabular}

Hasil pengujian pada hipotesis pertama (H1) dapat kita lihat pada tabel path coefficient dengan nilai $\mathrm{p}$ values memiliki besaran nilai 0.000 , nilai tersebut lebih kecil dari nilai alpha 0.050 yang membuktikan bahwa kepemimpinan melayani berpengaruh positif dan signifikan terhadap kinerja karyawan. Artinya semakin positif dan signifikan penerapan kepemimpinan melayani maka akan semakin positif dan signifikan pula kinerja karyawan. Temuan penelitian ini sejalan dengan penelitian terdahulu yang menyatakan bahwa terdapat hubungan yang kuat antara kepemimpinan melayani terhadap kinerja karyawan yang dikemukakan oleh (Harwiki, 2013) dan (Muhtasom et al., 2017). Bentuk kepemimpinan melayani adalah bentuk kepemimpinan yang paling ideal bagi bawahan dimana semakin ideal pemimpin bagi bawahahan akan semakin tinggi nilai dari kinerja bawahan. Implementasi bentuk kepemimpinan melayani pada PT Nesinak dapat dijelaskan belum bisa terimplementasi dengan baik karena tingkat kinerja 
karyawan pada perusahaan tersebut yang dapat dibilang rendah dimana target produksi yang ditetapkan oleh perusahaan yang masih belum dapat dicapai. Hal ini harus menjadi perhatian khusus bagi pihak manajemen karena melihat besarnya pengaruh bentuk kepemimpinan melayani terhadap kinerja karyawan yang sangat berpengaruh akan tercapainnya tujuan organisasi. Pengimplementasian bentuk kepemimpinan melayani pada PT Nesinak harus ditingkatkan agar kinerja karyawannya meningkat. Perusahaan harus memiliki strategi yang baik dalam mengimpelmentasikan bentuk kepemimpinan melayani pada setiap struktural kepemimpinan dalam perusahaan. Implementasi tersebut mulai dari tingkat kepemimpinan paling bawah (Line Leader) sampai tingkat kepemimpinan paling atas dalam perusahaan (President Director).

Hasil pengujian pada hipotesis kedua (H2) dapat kita lihat pada tabel path coefficient dengan nilai $\mathrm{p}$ values memiliki besaran nilai 0.087 , nilai tersebut lebih besar dari nilai alpha 0.050 yang membuktikan bahwa kepemimpinan melayani berpengaruh positif dan tidak signifikan terhadap kepercayaan. Temuan penelitian ini tidak sejalan dengan penelitian-penelitian terdahulu yang menyatakan bahwa kepemimpinan melayani mampu memberi contoh, tidak hanya membicarakan perkataannya, tetapi terus berjalan, berempati dan sepenuhnya menerima pengikut mereka, dan memperoleh kepercayaan pengikut melalui perilaku pemimpin yang melayani pengikutnya (Prasasti, 2014). Bentuk kepemimpinan melayani yang memberdayakan dan mengembangkan karyawan dengan sikap rendah hati, murni, dan penuh hormat akan membentuk kepercayaan yang kuat bagi bawahan. Dalam kepercayaan individu-individu yang memiliki kepercayaan yang tinggi terhadap organisasi akan berusaha semaksimal mungkin untuk mencapai tujuan organisasi. Penting bagi manajemen dalam meningkatkan kepercayaan bagi para setiap karyawannya, ini juga merupakan strategi yang baik bagi perusahaan yang bisa diterapkan pada PT Nesinak untuk meningkatkan kinerja organisasi.

Hasil pengujian pada hipotesis ketiga (H3) dapat kita lihat pada tabel path coefficient dengan nilai $\mathrm{p}$ values memiliki besaran nilai 0.000 , nilai tersebut lebih kecil dari nilai alpha 0.050 yang membuktikan bahwa kepercayaan berpengaruh positif dan signifikan terhadap kinerja karyawan. Artinya peningkatan kepercayaan secara positif searah terhadap kinerja karyawan dan berpengaruh signifikan terhadap kinerja karyawan. Temuan penelitian ini sejalan dengan penelitian-penelitian terdahulu yang menyatakan bahwa terdapat hubungan yang kuat antara kepercayaan terhadap kinerja karyawan (Roncesvalles \& Sevilla, 2015). Berdasarkan hasil penelitian yang dilakukan, peningkatan kepercayaan pada PT Nesinak dapat meningkatkan kinerja karyawan. Hal ini membuat peningkatan kepercayaan bagi setiap individu-individu pada PT Nesinak berpengaruh secara signifikan pada peningkatan kinerja masing-masing individu karyawan.

Pengaruh langsung antar variabel yang diuji pada penelitian ini dapat dilihat dari tabel 3 Path Coefficient sedangkan untuk melihat pengaruh tidak langsung (mediasi) dalam penelitian ini dapat di lihat pada tabel 4 Specific Indirect Effect. Berikut adalah tabel dari Specific Indirect Effect yang dapat menjelaskan pengaruh tidak langsung antar variabel yang diuji : 
Tabel 4. Specific Indirect Effect

\begin{tabular}{lccccc}
\hline & $\begin{array}{c}\text { Original } \\
\text { Sample (O) }\end{array}$ & $\begin{array}{c}\text { Sample } \\
\text { Mean (M) }\end{array}$ & $\begin{array}{c}\text { Standard Deviation } \\
(\text { STDEV) }\end{array}$ & $\begin{array}{c}\text { T Statistics } \\
(\mid \mathrm{O} / \mathrm{STDEV})\end{array}$ & $\begin{array}{c}\mathrm{P} \\
\text { Values }\end{array}$ \\
\hline $\begin{array}{l}\text { Kepemimpinan Melayani } \\
->\text { Kepercayaan }-> \\
\text { Kinerja Karyawan }\end{array}$ & 0.602 & 0.617 & 0.095 & 6.635 & 0.000 \\
\hline
\end{tabular}

Hasil pengujian pada hipotesis keempat (H4) dapat kita lihat pada tabel path coefficient dengan nilai $\mathrm{p}$ values memiliki besaran nilai 0.000 , nilai tersebut lebih kecil dari nilai alpha 0.050 yang membuktikan bahwa kepemimpinan melayani berpengaruh positif dan signifikan melalui kepercayaan terhadap kinerja karyawan. Artinya variabel kepercayaan dapat memediasi pengaruh kepemimpinan melayani terhadap kinerja karyawan. Temuan penelitian ini sejalan dengan penelitian terdahulu yang menyatakan bahwa kepercayaan dapat memediasi pengaruh kepemimpinan melayani terhadap kinerja karyawan (Setyaningrum et al., 2017). Berdasarkan hasil pengujian pengaruh tidak langsung antar variabel yang diuji dalam penelitian ini yang menyatakan bahwa variabel kepercayaan dapat memediasi pengaruh kepemimpinan melayani terhadap kinerja karyawan pada PT Nesinak yang tak lepas dari hasil pengujian pengaruh variabel kepercayaan terhadap kinerja karyawan yang didapati berpengaruh secara signifikan membuat hasil pengujian ini cukup beralasan. Variabel kepercayaan yang dapat memediasi pengaruh kepemimpinan melayani terhadap kinerja karyawan pada PT Nesinak merupakan bagian kecil dari sekian banyak variabel yang mempengaruhi kinerja karyawan secara langsung maupun tidak langsung yang tidak diuji pada penelitian ini. Hal ini memberikan kesempatan bagi para peneliti selanjutnya untuk kembali menguji model penelitian ini pada lain waktu atau menggunakan penelitian ini sebagai acuan dalam model-model penelitian lain.

\section{KESIMPULAN}

Kepemimpinan melayani berpengaruh positif dan signifikan terhadap kinerja karyawan, hal ini ditunjukan dengan nilai $\mathrm{p}$ values memiliki besaran nilai 0.000 , nilai tersebut lebih kecil dari nilai alpha 0.050 . Kepemimpinan melayani berpengaruh positif dan tidak signifikan terhadap kepercayaan, hal ini ditunjukan dengan nilai $\mathrm{p}$ values memiliki besaran nilai 0.087 , nilai tersebut lebih besar dari nilai alpha 0.050. Kepercayaan berpengaruh positif dan signifikan terhadap kinerja karyawan, hal ini ditunjukan dengan nilai p values memiliki besaran nilai 0.000 , nilai tersebut lebih kecil dari nilai alpha 0.050. Kepemimpinan melayani berpengaruh positif dan signifikan terhadap kinerja karyawan melalui kepercayaan, hal ini ditunjukan dengan nilai $\mathrm{p}$ values memiliki besaran nilai 0.000 , nilai tersebut lebih kecil dari nilai alpha 0.050. Penelitian ini hanya menguji dua variabel dari sekian banyak variabel yang berpengaruh terhadap kinerja karyawan sehingga masih banyak variabel-variabel yang lain untuk kembali diuji dengan model yang sama atau tidak seperti dalam penelitian ini dimasa yang akan datang. Tingkat kinerja karyawan pada PT Nesinak yang dapat dibilang rendah membuktikan bahwa pengimplementasian bentuk kepemimpinan melayani yang mempunyai pengaruh cukup besar terhadap kinerja karyawan pada perusahaan tersebut masih belum efektif, manajemen atau perusahaan harus memperhatikan masalah ini sehingga upaya peningkatan kinerja karyawan dapat terealisasikan. Variabel kepercayaan dalam penelitian ini yang terbukti tidak berpengaruh secara signifikan terhadap kinerja 
karyawan tidak boleh diabaikan oleh manajemen atau perusahaan karena variabel kepercayaan dapat berpengaruh secara langsung maupun tidak langsung terhadap variabel-variabel lain yang tidak diuji dalam penelitian ini yang berpengaruh pada kinerja karyawan. Upaya peningkatan kinerja karyawan yang sangat berpengaruh pada kinerja organisasi pada masing-masing perusahaan memiliki cara yang berbeda-beda. Hasil dari penelitian ini memberikan sedikit gambaran bagi PT Nesinak dan perusahaan lainnya untuk menyusun strategi dalam upaya peningkatan kinerja karyawan dengan melibatkan variabel kepemimpinan melayani dan kepercayaan yang terbukti dapat meningkatkan kinerja karyawan, walaupun kepercayaan dalam penelitian ini tidak terbukti dapat berpengaruh secara signifikan akan tetapi peningkatan tingkat kepercayaan secara positif searah dengan peningkatkan kinerja karyawan walaupun tidak berpengaruh secara signifikan.

\section{DAFTAR PUSTAKA}

Altındağ, E., \& Kösedağı, Y. (2015). The Relationship Between Emotional Intelligence of Managers, Innovative Corporate Culture and Employee Performance. Procedia - Social and Behavioral Sciences, 210, 270-282. https://doi.org/10.1016/j.sbspro.2015.11.367

Bakiev, E. (2013). The influence of interpersonal trust and organizational commitment on perceived organizational performance. Journal of Applied Economics and Business Research, 3(3), 166-180.

Brown, S., Gray, D., McHardy, J., \& Taylor, K. (2015). Employee trust and workplace performance. Journal of Economic Behavior \& Organization, 116, 361-378.

Bryant, P., \& Brown, S. (2015). Moving Servant Leadership Forward: One Issue at a Time.

Cania, L. (2014). The impact of strategic human resource management on organizational performance. Economia. Seria Management, 17(2), 373-383.

Dartey-Baah, K. (2015). Resilient leadership: a transformational-transactional leadership mix. Journal of Global Responsibility, 6(1), 99-112. https://doi.org/10.1108/jgr07-2014-0026

Harwiki, W. (2013). The Influence of Servant Leadership on Organization Culture, Organizational Commitment, Organizational Citizenship Behavior and Employeesâ $€^{\mathrm{TM}}$ Performance (Study of Outstanding Cooperatives in East Java Province, Indonesia). Journal of Economics and Behavioral Studies, 5(12), 876885. https://doi.org/10.22610/jebs.v5i12.460

Joseph, E. E., \& Winston, B. E. (2005). A correlation of servant leadership, leader trust, and organizational trust. Leadership \& Organization Development Journal.

King, D. D., Newman, A., \& Luthans, F. (2016). Not if, but when we need resilience in the workplace. Journal of Organizational Behavior, 37(5), 782-786. 
Liden, R. C., Wayne, S. J., Liao, C., \& Meuser, J. D. (2014). Servant leadership and serving culture: Influence on individual and unit performance. Academy of Management Journal, 57(5), 1434-1452. https://doi.org/10.5465/amj.2013.0034

Mathis, R. L., Jackson, J. H., \& Valentine, S. R. (2015). Human resource management: Essential perspectives. Cengage Learning.

Muhtasom, A., Mus, H. A. R., Bijang, J., \& Latief, B. (2017). Influence of Servant Leadership, Organizational Citizenship Bahaviour on Organizational Culture and Employee Performance at Star Hotel in Makassar. Star, 486(206), 410.

Olesia, W. S., Namusonge, G. S., \& Iravo, M. A. (2014). Servant leadership: the exemplifying behaviours. IOSR Journal Of Humanities And Social Science (IOSRJHSS) Vol, 19, 75-80.

Paliszkiewicz, J. (2012). Managers' orientation on trust and organizational performance. Jindal Journal of Business Research, 1(2), 153-161.

Prasasti, V. (2014). Pengaruh Kepemimpinan Melayani terhadap Kepercayaan Organisasi yang Dimediasi oleh Komunikasi Organisasi. Universitas Kristen Maranatha.

Rai, R., \& Prakash, A. (2012). A relational perspective to knowledge creation: Role of servant leadership. Journal of Leadership Studies, 6(2), 61-85.

Rezaei, M., Salehi, S., Shafiei, M., \& Sabet, S. (2012). servant leadership and organizational trust: the mediating effect of the leader trust and organizational communication. emaj: Emerging Markets Journal, 2(1).

Robbins, S. P., \& Judge, T. A. (2017). Organizational Behavior, Seventeenth Edition, Global Edition. Pearson Education Limited.

Roncesvalles, M. C. T., \& Sevilla, A. V. (2015). The impact of authentic leadership on subordinates' trust and work performance in educational organization: A structural equation modeling (SEM). University of Santo Tomas.

Setyaningrum, R. P., Setiawan, M., \& Surachman, S. (2017). Organizational commitments are mediation of relationships Between servant leadership and employee performance. Jurnal Aplikasi Manajemen, 15(4), 693-701.

Shekari, H., \& Nikooparvar, M. Z. (2012). Promoting Leadership Effectiveness in Organizations: A Case Study on the Involved Factors of Servant Leadership. International Journal of Business Administration, 3(1), 54-65. https://doi.org/10.5430/ijba.v3n1p54

Thigpen, M. L., Beauclair, T. J., Keiser, G. M., \& Faust, D. (2012). US Department of Justice National Institute of Corrections 320 First Street, NW Washington, DC 20534. 
van Dierendonck, D., \& Nuijten, I. (2011). The Servant Leadership Survey: Development and Validation of a Multidimensional Measure. Journal of Business and Psychology, 26(3), 249-267. https://doi.org/10.1007/s10869-010-9194-1

Yukl, G. (2013). Leadership in organizations Eighth edition Upper Saddle River. New Jersey: Prentice Hall. 